\title{
Sentidos de Qualidade na Política de Currículo (2003-2012)
}

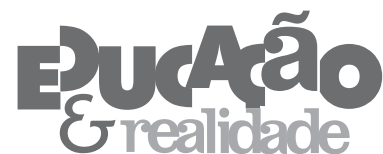

Danielle dos Santos Matheus'

Alice Casimiro Lopes'

'Universidade do Estado do Rio de Janeiro (UERJ), Rio de Janeiro/RJ - Brasil

RESUMO - Sentidos de Qualidade na Política de Currículo (2003-2012). Este artigo apresenta os resultados de uma investigação sobre os sentidos de qualidade da educação vinculados ao currículo na política educacional no período entre 2003 e 2012. Operando com a teoria do discurso, defendemos que a articulação entre o discurso de qualidade que se pretende total e o discurso de qualidade social é favorecida pela equivalência estabelecida entre as demandas relativas ao conhecimento. Como superfícies de inscrição de sentidos da política, são analisados 57 documentos produzidos no âmbito do Ministério da Educação no referido período e textos de programa de governo divulgados pelo Partido dos Trabalhadores na ocasião das campanhas eleitorais de 2002, 2006 e 2010.

Palavras-chave: Conhecimento. Política de Currículo. Qualidade da Educação. Discurso. Educação Básica.

ABSTRACT - Meanings of Quality in the Curriculum Policy (2003-2012). This paper presents the results of a research into the meanings of quality of education associated with curriculum in the period 2003-2012. Dealing with theory of discourse, it is argued that the articulation between the discourse of quality that intends to be total and the discourse of social quality is favored by the equivalence between demands of knowledge. Like surfaces of inscription of political meanings, 57 documents from Ministry of Education of this period are analyzed. The Work Party political platforms of electoral campaign in 2002, 2006 and 2010 are also analyzed.

Keywords: Curriculum Policy. Knowledge. Quality of Education. Discourse. K-12 Education.

Educação \& Realidade, Porto Alegre, v. 39, n. 2, p. 337-357, abr./jun. 2014 


\section{Introdução}

Este artigo apresenta parte dos resultados de uma investigação mais ampla do discurso da política de currículo para a educação básica durante o período 2003-2012, na vigência do governo de Luís Inácio Lula da Silva, com sentidos que se mantêm no período atual, durante o governo Dilma Roussef, iniciado em 2011. Para análise de tal discurso, foram acessados 57 documentos ${ }^{1}$ produzidos no âmbito do Ministério da Educação no referido período, um documento do CONED (Congresso Nacional de Educação) ${ }^{2}$ e os textos de programa de governo divulgados pelo Partido dos Trabalhadores na ocasião das campanhas eleitorais de 2002, 2006 e 2010.

Durante o período do governo Fernando Henrique Cardoso, foi instituído um projeto de centralidade curricular, frequentemente denominado neoliberal: parâmetros curriculares nacionais, avaliação de livros didáticos, sistemas nacionais de avaliação. Muitas foram as críticas de curriculistas brasileiros a essas propostas ${ }^{3}$ e houve grande expectativa por parte de movimentos sociais e de pesquisadores do campo do Currículo de que esse quadro se modificasse com a mudança de governo. Afinal, a política educacional que o Governo Lula se propôs a forjar, em seu primeiro mandato, buscava se contrapor às políticas de educação instauradas nos governos anteriores, que, segundo o discurso do projeto petista, foram incapazes de universalizar a educação com qualidade. A intenção era (e ainda é) a de se instituir como um corte antagônico ao projeto do governo Fernando Henrique Cardoso, tendo sido esta a marca do Plano de Governo de Lula, na campanha de 2002.

No que concerne às políticas de currículo do período aqui investigado, entretanto, houve acentuada continuidade dos mecanismos de centralização do poder ${ }^{4}$ e mesmo um acirramento, com propostas de currículo único ${ }^{5}$ e aprofundamento da utilização do Exame Nacional do Ensino Médio (ENEM) para acesso ao ensino superior. A difusão de pronunciamentos que apontam para a valorização de rankings das escolas não é obrigatoriamente realizada por ações governamentais, mas é destacada pela mídia e pelas próprias instituições escolares que apresentam resultados favoráveis, não encontrando contraponto em pronunciamentos governamentais. As críticas a esses mecanismos de centralização, ainda que existam, não se multiplicam nem assumem o destaque dos anos 1990. Temos o que pode ser considerado como a hegemonização de um projeto de centralidade curricular, com certo silenciamento de críticas por diferentes mecanismos simbólicos que merecem ser investigados em outro momento.

Sintonizadas com trabalhos da área (Lopes, 2004; 2008; 2010, por exemplo), ao falar da hegemonização de uma política de currículo centralizada, não nos referimos a um processo no qual as instituições educacionais do governo federal são tomadas como centros de onde emanam os discursos. Estamos nos referindo a um processo discursivo 
descentrado que tem os textos curriculares assinados pelo Ministério como mais uma de suas representações. É por intermédio desse enfoque que defendemos haver uma teoria curricular que subsidia os textos das políticas e, dessa forma, nos torna, também, produtores de sentidos para as políticas em curso, sempre em complexos processos de tradução. A colaboração direta de pesquisadores do campo do currículo na escrita desses textos só reforça a posição que assumimos a respeito dos nexos entre teorias e políticas de currículo. Nesse sentido, todo texto educacional é, em alguma medida, um texto político, compõe a textualidade da política. Ao investigarmos esses textos, somos então mobilizadas pela possibilidade de ler essa tradução como campo discursivo que não tem seus sentidos fixados - a leitura sempre pode ser outra, mas é possibilitada por um dado modo de interpretar instituído (Bowman, 2007).

Ao nomearmos essa política como um projeto de centralidade curricular, buscamos nos referir à constituição de um discurso produzido pela articulação de diferentes demandas sociais no período 2003-2012, considerando borrados os limites temporais aqui estabelecidos. Rastros de outras épocas, no sentido derridiano, mostram-se como espectros que se inserem discursivamente na contemporaneidade (Wolfreys, 2009). Há ações dos governos Lula e Dilma - como houve no governo Fernando Henrique Cardoso - que buscam produzir um centro na política curricular. Igualmente são conhecidas as verbas internacionais garantidoras da infraestrutura para esses propósitos. O discurso, contudo, não se limita a essas ações. Tal discurso se institui por uma ampla articulação a qual podemos fazer referência por um significante genérico-um nome - aglutinador de sentidos.

Não buscamos focalizar, portanto, quais as práticas governamentais que sustentam esse discurso, ainda que não desmereçamos o quanto os discursos estão imbricados a essas práticas. Tampouco interessa-nos investigar as fontes de financiamento das políticas. Não apenas porque outros autores já se dedicaram a esse foco, como por não concebermos que tais dimensões, por si só, sustentam os sentidos da política curricular. Interessa-nos compreender os sentidos curriculares e pedagógicos que garantem tais articulações, as operações linguísticas que tornam possível a hegemonização de determinados sentidos da política. Localizamos pontualmente o discurso em que noções de conhecimento relevante são imbricadas às finalidades avaliativas tornando tais noções equivalentes à de conhecimentos verificáveis. É com esse movimento que julgamos ser possível desconstruir o que está sedimentado como imaginário pedagógico do qual não parece ser possível nos desvencilharmos.

Em sintonia com uma compreensão discursiva e pós-fundacionalista do currículo, buscamos enfraquecer o status ontológico dos fundamentos, com a consequente introdução do político (the political) como momento de atualização dos fundamentos, um empreendimento ao mesmo tempo impossível e necessário (Marchart, 2007). 
Dedicamo-nos a analisar como se desenvolve/mantém, no momento atual, a hegemonização do projeto de centralidade curricular e que demandas articuladas vêm contribuindo para tal processo. Exploramos a compreensão da política de currículo como luta discursiva pela constituição de representações, por meio da análise de discursos curriculares nas políticas. Se entendemos a negociação nas políticas de currículo como articulação discursiva, estamos afirmando que diferentes demandas curriculares particulares são capazes de articular-se entre si, de forma provisória e contingente. Desta maneira, constituem dadas representações e grupos sociais para o currículo.

Ao investigarmos o significante qualidade da educação, defendemos que os discursos curriculares hegemônicos tendem a se desenvolver por intermédio da construção de um antagonismo a uma dada representação de currículo. O currículo que se busca introduzir está marcado pela ideia da inovação, é visto como um progresso em relação ao que é (vinha sendo) realizado, por antagonizar-se a uma negatividade que se quer superar. A fronteira entre o que se projeta e o que se deseja superar se constrói por meio de significantes vazios (Laclau, 2011). Investigamos o esvaziamento de sentidos do significante qualidade da educação como um dos mecanismos de constituição da hegemonia da política de currículo centralizada. São tantas as demandas sociais em relação ao que vem a ser qualidade da educação, desde aquelas sintonizadas com as condições socioeconômicas de vida até as relações interpessoais nos lugares de trabalho, que a qualidade se esvazia de significado. É por meio desse vazio, nunca completo, sempre tendencialmente vazio, que a expressão qualidade da educação se torna capaz de aglutinar diferentes demandas e constituir diferentes sujeitos que atuam em seu nome, contrapondo-se a uma ideia de escola sem qualidade. Não se atribui aqui um sentido de negatividade ao esvaziamento. Defendemos ser desse modo político que se opera e se produz hegemonia.

Cabe compreender, portanto, o processo de representação desse antagonismo, uma vez que não há atores sociais que defendam uma educação sem qualidade. Mas ainda assim se constrói uma representação do inimigo a ser enfrentado a partir do que lhe falta. Não há nenhuma característica objetiva que lhe seja inerente. Por mais que sejam enumeradas as características desse inimigo, elas não se associam exclusivamente a ele nem caracterizam de forma objetiva a ausência de qualidade, dadas as inumeráveis diferenças que permitem essa significação.

Exploramos especificamente neste artigo diferentes sentidos de qualidade postos em circulação no momento atual, analisando como vem se dando a articulação entre dois discursos de qualidade inicialmente construídos como antagônicos: o discurso da qualidade que se pretende total, difundido, em parte, com apoio de grupos empresariais, e o discurso de qualidade social, constituído, também em parte, por movimentos sociais. Exploramos a problemática da identidade/subjetiva- 
ção desses grupos mais adiante. Defendemos que tal articulação produz a hegemonia de um discurso centralizado na política curricular e limita as possibilidades de constituição de outros imaginários pedagógicos. Buscamos examinar os mecanismos que tornam possível tal articulação, com destaque para as demandas equivalenciais em torno do significante conhecimento. Tendo em vista esse propósito, desenvolvemos inicialmente uma análise dos antagonismos entre projetos de qualidade anteriores ao período do primeiro governo Lula e posteriormente apresentamos como entendemos que vem se construindo nos últimos anos a relação entre currículo e qualidade.

\section{Antagonismo entre Projetos de Qualidade}

A defesa da qualidade da educação não é um projeto novo e tampouco pode ser associada exclusivamente ao período aqui focalizado (2003-2012). Na constante tentativa de mobilização social em torno da educação, reiteradamente a qualidade do currículo é afirmada como parte da luta de todos, projetando uma unidade social e um consenso curricular imaginários. Estar na escola e alcançar níveis instrucionais comuns a todos os alunos, evidenciados por exames nacionais e internacionais, são naturalizados como expressão da qualidade do currículo e, portanto, da educação. Ball (1994) já salientou o quanto as reformas educacionais tendem a ser analisadas em função de sua capacidade de atingir finalidades de primeira ordem, vinculadas aos objetivos instrucionais, e com isso deixam de ser analisadas suas finalidades de segunda ordem, vinculadas às possibilidades, por exemplo, de ampliar o que pode ser entendido contextualmente como maior justiça social. Efeitos intangíveis, que escapam à métrica e ao cálculo, vinculados à dimensão cultural na qual a educação se inscreve, tendem a ser desconsiderados na análise das políticas educacionais.

O discurso de qualidade foi especialmente difundido nas propostas de qualidade total dos anos $1990^{6}$, marcadas por uma estreita relação entre os modos de operar da escola e as dinâmicas empresariais, mas não se limita a esse período. Como exemplo emblemático mais recente, o movimento Todos pela Educação $o^{7}$ associa as metas de qualidade ao processo de inclusão escolar, reduzindo a defasagem idade-série, e ao alcance de índices instrucionais adequados, a partir de critérios estabelecidos em testes centralizados, principalmente o Sistema de Avaliação da Educação Básica (SAEB), do Ministério da Educação (MEC) e a Avaliação Brasileira do Final do Ciclo de Alfabetização (Prova ABC), organizada pelo Instituto Nacional de Estudos e Pesquisas Educacionais (INEP/MEC), pelo IBOPE e pela Fundação Cesgranrio.

Dados os conflitos em torno do currículo que se deseja projetar, tal discurso de qualidade é antagonizado por diferentes agendas de movimentos sociais e da comunidade educacional. Tentando se afastar dessa significação instrucional, múltiplas ações são desenvolvidas na

Educação \& Realidade, Porto Alegre, v. 39, n. 2, p. 337-357, abr./jun. 2014

Disponível em: <http://www.ufrgs.br/edu_realidade> 
construção de um projeto de qualidade social por meio da afirmação de uma educação crítica.

A educação é aqui entendida como um instrumento de formação ampla, de luta pelos direitos da cidadania e da emancipação social, preparando as pessoas e a sociedade para a responsabilidade de construir, coletivamente, um projeto de inclusão e de qualidade social para o país (II Congresso Nacional de Educação, CONED, 1997, grifo nosso).

O conhecimento é afirmado como comprometido com questões sociais, buscando vincular o currículo e a qualidade da educação à transformação social e esta a um projeto de Nação. É realizada a tentativa de fixar um sentido de qualidade que se diferencie de um discurso de eficiência e eficácia, característico das concepções instrumentais de educação.

Como afirma Marchart (2007), sem antagonismo não há possibilidade de que o sentido seja produzido. É pelo antagonismo ao discurso de qualidade que se pretende total que o discurso de qualidade social se institui. É pela negatividade ao projeto da qualidade vinculada a critérios instrumentais que a identidade da qualidade social se projeta. É em relação ao que se pretende expulsar de seu campo de lutas que a articulação se faz. Ou ainda, é pela redução do Outro ao discurso do mercado, do empresariado, da tecnocracia, que o discurso da qualidade social se potencializa e se instaura como possibilidade democrática: a construção coletiva de todos, os trabalhadores.

A qualidade social traduz-se na oferta de educação escolar e de outras modalidades de formação para todos, com padrões de excelência e adequação aos interesses da maioria da população. Tem como consequência a inclusão social, por meio da qual todos os brasileiros se tornam aptos ao questionamento, à problematização, à tomada de decisões, buscando soluções coletivas possíveis e necessárias à resolução dos problemas de cada um e da comunidade em que se vive e trabalha. Quem define tal qualidade é a comunidade escolar, são os especialistas e estudiosos, os trabalhadores, enfim, toda a sociedade envolvida no processo formativo. É exatamente a prática da construção coletiva que nos tem diferenciado de outros governos, especialmente do atual governo federal e de seus conceitos utilitaristas (Partido dos Trabalhadores, 2002, p. 8-9).

O adjetivo social é assim vinculado ao que é para todos (a maioria da população, toda sociedade, o coletivo) buscando restringir o adjetivo total ao que é para poucos - os privilegiados que se beneficiam da exclusão social, da escola sem qualidade. Ambos os discursos - o da qualidade que se pretende total e o da qualidade social - se consolidam porque se ampliam, produzem equivalências entre múltiplas demandas cons- 
tituídas. Não mais é possível afirmar que cabe um discurso ao empresariado e outro, aos trabalhadores, fixando identitariamente tais grupos. Identificar os atores sociais que são subjetivados por esses discursos é tarefa contextual que depende do estudo das articulações políticas engendradas no processo e dos sentidos que são mobilizados quando se defende a qualidade: não são os grupos sociais que produzem os discursos, mas os discursos que forjam os grupos nos quais são subjetivados os múltiplos atores sociais (Laclau, 2005). Afirmar que um dado grupo social se vincula a um discurso é mais uma estratégia retórica, capaz de favorecer o antagonismo a esse discurso e a criação de equivalências entre as demandas críticas a ele, do que uma análise dos processos de subjetivação produzidos por esse discurso.

Defendemos, assim, que se constituem duas cadeias de equivalência: uma entre as demandas curriculares voltadas ao que vem sendo caracterizado como metas objetivas de inclusão e aprendizado e outra, entre demandas curriculares que, sem desmerecerem as metas de inclusão, tentam projetar o conhecimento como associado às reconhecidas bandeiras da perspectiva crítica em educação e em currículo. Para tal, essa segunda cadeia de equivalências projeta a qualidade como social e busca, pela inserção do adjetivo, expulsar os sentidos instrumentais vinculados à primeira cadeia enunciada, na qual estariam os projetos reduzidos aos enfoques objetivistas.

No caso da primeira cadeia de equivalências, os sentidos de qualidade tendem a ser fixados a metas instrucionais que se pretendem precisas. A qualidade é significada por intermédio de mecanismos que tentam controlar o conhecimento escolar e se torna um conjunto de índices com base em diagnósticos supostos inquestionáveis. É constituído um discurso que busca sua universalização introduzindo a dinâmica de ser necessário para o desenvolvimento do país, da sociedade como um todo, para o bem comum. Na mesma cadeia também se incluem, por exemplo, demandas dos que buscam emprego, ascensão social e concebem tais possibilidades como vinculadas ao alcance dos parâmetros instrucionais instituídos. Os sentidos da formação para o mercado e os sentidos da busca de empregabilidade são tornados equivalentes pela própria flutuação de significantes como eficiência, bem comum e desenvolvimento.

Por sua vez, no caso da segunda cadeia de equivalências - em torno da qualidade social -, a mobilização popular crescente aglutinada por demandas dos grupos que visavam levar o Partido dos Trabalhadores à Presidência da República, sucumbiu - e ainda sucumbe - à indeterminação e à imprecisão de tradicionais bandeiras de luta.

A qualidade social implica providenciar educação escolar com padrões de excelência e adequação aos interesses da maioria da população. Tal objetivo exige um grande esforço da sociedade e de cada um para ser atingido, considerando as dificuldades impostas pela atual conjuntura. De 
acordo com essa perspectiva, são valores fundamentais a serem elaborados: solidariedade, justiça, honestidade, autonomia, liberdade e cidadania (CONED, 1997, p. 10).

Tal flutuação de sentidos não se desenvolve por erro de cálculo, por qualquer equívoco, mas pelo jogo político (de linguagem) caracterizado pelo excesso da significação e, assim, pelo esvaziamento dos significantes garantidores da articulação pretendida. Na luta por hegemonia, os processos articulatórios fazem com que a qualidade perca relação com conteúdos precisos e concretos, tornando-se capaz de vir a subverter a estrutura do signo (Laclau, 2005; 2011). Como qualquer discurso com pretensões universalizantes, em ambas as cadeias de equivalências são obscurecidas as marcas contingentes dos interesses das instituições e atores sociais envolvidos na sua constituição (Laclau, 2011).

O jogo político, todavia, não cessa pela ocupação de cargos do Poder Executivo e outras articulações se fazem em torno do projeto de qualidade da educação, na medida em que é modificada a configuração dos grupos do governo e as relações sociais.

\section{Demandas de um Projeto de Qualidade da Educação}

Promover a qualidade da educação é o objetivo central da política educacional no período 2003-2012, constituindo-se tal qualidade como direito (Brasil, 2009c; 2009a; 2009b; 2006c; 2010) que deve ser assegurado (Brasil, 2009c; 2009b; 2011; 2009a; 2006b; 2006c) e garantido (Brasil, 2009c; 2009b; 2010; 2007c; 2009d; 2011) pelo poder público e escolas. A almejada educação de qualidade destina-se a todos (Brasil, 2009c; 2009b; 2009d; 2007a; 2011; 2010; 2007c), mas não se restringe ao acesso à escola. Esse passa por universalizar a permanência e a conclusão de cada etapa de ensino com qualidade (Brasil, 2009c; 2009b) que esteja referenciada na garantia das condições necessárias à aprendizagem de todos.

O fomento à qualidade entra na esteira do crescimento econômico que o Brasil tem vivenciado durante esses governos e visa a sustentar o ciclo de desenvolvimento do país (Brasil, 2011). O desenvolvimento econômico traz consigo novas demandas e "[...] a educação, sem dúvida, está no centro desta questão" (Brasil, 2011, p. 1), como um desafio a ser vencido (Brasil, 2004a; 2006a; 2003) e, ao mesmo tempo, uma conquista (Brasil, 2011; 2010). A almejada educação de qualidade produziria um efeito cascata de melhorias, que tende a ser resumido na seguinte equação: uma melhor/maior qualidade da educação resulta em maior desenvolvimento dos alunos (Brasil, 2006c) e, consequentemente, em maior/melhor desenvolvimento do país, de forma que seja possível dar um salto para o futuro (Brasil, 2011).

A escola de qualidade, como possibilidade de acesso de todos ao conhecimento, é considerada como "[...] crucial para que a possibilidade da transformação social seja concretizada" (Brasil, 2011, p. 25). 
Acredita-se que a educação de qualidade, realmente, tenha importante papel “[...] no processo de mobilidade social e superação das divisões da sociedade brasileira" (Brasil, 2008c, p. 110). A educação é tida como condição essencial de inclusão e democratização das oportunidades no país (Brasil, 2006a).

Os ideais de transformação social abarcam uma miríade de demandas sociais, políticas e econômicas que passam pela redução da pobreza (Brasil, 2009c; 2009b), “[...] diminuição de desigualdades socioeconômicas estruturais" (Brasil, 2008c, p. 111), construção de uma sociedade mais justa, solidária e igualitária (Brasil, 2009c; 2009b), desenvolvimento econômico e sustentabilidade do país; consolidação da cidadania do povo (Brasil, 2006a), “[...] construção de um Brasil ético, justo, livre e democrático” (Brasil, 2009d, p. 60).

Esse projeto de qualidade se constitui como decorrente da articulação de demandas sociais e educacionais. Por demandas sociais entendemos as que se referem a um projeto de sociedade que se intenta concretizar pela via da educação de qualidade. As demandas sociais dizem respeito à construção de uma sociedade mais justa. Justiça social é uma demanda que está ligada ao fim das desigualdades sociais, à inclusão social, ao respeito à diversidade cultural e à redução da pobreza.

As demandas educacionais são as que dizem respeito às questões de ensino, os avanços pretendidos no âmbito pedagógico e que caracterizam o que se entende por um ensino de qualidade. As principais demandas educacionais são a promoção da efetiva aprendizagem por parte dos alunos, o acesso e a permanência de todos na escola, a redução da distorção série-idade, a eliminação da reprovação, a igualdade de acesso ao conhecimento a todos, a equidade de oportunidades de ensino e a classificação de todos no IDEB (Índice de Desenvolvimento da Educação Básica) sob o valor 6.0, no mínimo ${ }^{8}$.

Demandas educacionais e sociais estão inter-relacionadas, sendo significadas numa relação de causa e efeito: as demandas educacionais, quando satisfeitas, produzirão as condições necessárias à satisfação das demandas sociais. "O sistema educacional deve ter como meta a promoção do aumento dos níveis de escolarização da sua população, capacitando-a para atuar de forma crítica e responsável na construção de uma sociedade mais justa, democrática e desenvolvida” (Brasil, 2004a, p. 27). A relação de causa e efeito entre demandas sociais e educacionais tanto é construída pela inclusão da educação de qualidade na agenda do desenvolvimento do país como produz formações discursivas que a viabilizam.

No primeiro programa da campanha de Lula à Presidência, a educação é tomada como "[...] um instrumento fundamental para o desenvolvimento e a inserção competitiva de qualquer nação no mundo” (Partido dos Trabalhadores, 2002, p. 37). No programa subsequente, o mandato de Lula foi nomeado "desenvolvimento com distribuição de 
renda e educação de qualidade” (Partido dos Trabalhadores, 2007, p. 5), um “[...] desenvolvimento de longa duração, com redução das desigualdades sociais e regionais, [...] ênfase na educação [...]” (Partido dos Trabalhadores, 2007, p. 7). O mesmo tom foi mantido no programa de Dilma Roussef, no sétimo dos treze compromissos anunciados: "Garantir educação para a igualdade social, a cidadania e o desenvolvimento" (Partido dos Trabalhadores, 2010, p. 7).

É interessante apontar que o inverso não é enfatizado nos documentos curriculares e programas de governo. Não se defende que o atendimento às demandas sociais impulsiona o atendimento às demandas educacionais, ou que uma sociedade mais justa é capaz de favorecer o processo de instituir uma educação de qualidade. Na tradução construída, os vínculos entre qualidade da educação e desenvolvimento social são potencializados pelos vínculos entre qualidade da educação e qualidade do currículo/conhecimento escolar. O discurso de qualidade do currículo, por sua vez, se constitui pela articulação entre os discursos anteriormente antagônicos: discurso da qualidade social e o discurso da qualidade que se quer total, em uma equivalência pedagogicamente garantida pelos sentidos conferidos ao conhecimento.

\section{Articulação entre Diferentes Cadeias Equivalenciais de Qualidade}

Nos documentos curriculares atuais, o discurso da qualidade social da educação é ancorado na tríade acesso/permanência/sucesso do aluno na escola, sendo significada como uma demanda de todos e para todos por meio de sua vinculação às lutas de movimentos sociais. Em torno dessa tríade é feito o apelo ao acordo e à mobilização coletiva, visando a "[...] educação escolar comprometida com a igualdade de acesso ao conhecimento a todos e, especialmente empenhada em garantir esse acesso aos grupos da população em desvantagem na sociedade” (Brasil, 2009, p. 49).

Os significantes carreiam traços de demandas de movimentos sociais, pelo foco "[...] na cidadania e na dignidade da pessoa, o que implica igualdade, liberdade, pluralidade, diversidade, respeito, justiça social, solidariedade e sustentabilidade" (Brasil, 2010, p. 11), mas também os traços de demandas instrucionais. São os conhecimentos escolares vinculados às disciplinas que permanecem orientando as avaliações centralizadas nos resultados.

\footnotetext{
A excessiva preocupação com os resultados desses testes, sem maior atenção aos processos pelos quais as aprendizagens ocorrem, também termina obscurecendo aspectos altamente valorizados nas propostas da educação escolar que não são mensuráveis como, por exemplo, a autonomia, a solidariedade, o compromisso político e a cidadania, além do próprio ensino da história e da geografia e o
} 
desenvolvimento das diversas áreas de expressão (Brasil, 2009c, p. 62).

O documento se institui apoiado em uma concepção de currículo centrada no aluno, no conhecimento e em sua aprendizagem. O currículo da escola de qualidade social deve estar alicerçado em princípios

[...] orientados pela liberdade de aprender, ensinar, pes-
quisar e divulgar a cultura, o pensamento, a arte e o co-
nhecimento científico, além do pluralismo de ideias e de
concepções pedagógicas, assim como a valorização da
experiência extraescolar, e a vinculação entre a educação
escolar, o trabalho e as práticas sociais (Brasil, 2010, p. 19).

É destacada a base nacional comum, e nela o conhecimento. São mencionadas outras dimensões da cultura, mas prevalece a leitura de que a cultura é um repertório de conteúdos. São os conteúdos, vinculados às disciplinas atualmente presentes na escola, que são enunciados como capazes de garantir a qualidade social.

Os conhecimentos escolares que, por exigência da cidadania, têm caráter obrigatório, conforme o artigo 26 da $\mathrm{LDB} / 96$, são aqueles que dizem respeito à compreensão do mundo físico e natural e da realidade social e política, com destaque a vida social e política contemporânea e a história do Brasil; ao estudo da matemática; a aquisição de habilidades de expressão e comunicação e ao desenvolvimento de linguagens que passam pelo domínio da língua portuguesa e pelas diversas manifestações artísticas e práticas corporais (Brasil, 2009, p. 65).

A avaliação é defendida como capaz de contribuir para a melhoria da qualidade da educação (Brasil, 2009d), considerando-se necessário instituir um instrumento para "[...] acompanhar a evolução do trabalho desenvolvido nas escolas, e prevenir, assim, o diagnóstico tardio dos baixos níveis de alfabetização e letramento" (Brasil, 2008b, p. 5). Os processos de avaliação nacional que compõem o SAEB são concebidos como forma de colaborar para a melhoria da qualidade da educação (Brasil, 2003; 2011d; 2009c; 2005; 2004b; 2009b).

A qualidade do conteúdo aprendido nas escolas é verificada por meio de avaliações para medir as competências e as habilidades desenvolvidas pelos alunos. O processo guarda semelhanças ao que os professores fazem para avaliar se seus alunos aprenderam ou não uma determinada matéria. O Sistema Nacional de Avaliação da Educação Básica (Saeb) apresenta testes de habilidades e competências, construídos por especialistas de cada área, e utiliza as mais avançadas técnicas estatísticas para diagnosticar o nível educacional de determinadas séries (Brasil, 2004b, p. 11).

Educação \& Realidade, Porto Alegre, v. 39, n. 2, p. 337-357, abr./jun. 2014

Disponível em: <http://www.ufrgs.br/edu_realidade> 
A qualidade deve ser balizada por critérios pelos quais as instituições serão avaliadas (Brasil, 2009e). Tais critérios têm relação com a adoção de um padrão mínimo de qualidade a ser garantido pelo poder público a todos, um padrão que está ligado à ideia de equalização das oportunidades (Brasil, 2006b), bem como à criação de um ambiente propício à aprendizagem.

Introduzir para as escolas um padrão de qualidade que transcenda os governos e a dinâmica de alternância de poder e que considere as especificidades da Educação Básica (Brasil, 2009d) é considerado um desafio e, nesse sentido, duas vias de atuação são apontadas: o investimento financeiro e o currículo (Brasil, 2010). Os parâmetros, na referida política, são padrões de referência para a supervisão, o controle social e a avaliação da educação e para o redirecionamento do trabalho em cada instituição e sistema de ensino (Brasil, 2006b) e visam a "[...] melhorar a eficiência e garantir a generalização da qualidade do atendimento" (Brasil, 2006b, p. 22).

Alguns documentos sinalizam a definição de indicadores de qualidade com base nesses parâmetros, como um desdobramento desejado. Os indicadores buscam traduzir e detalhar os parâmetros de qualidade em indicadores operacionais. São “[...] sinais que revelam aspectos de determinada realidade e que podem qualificar algo" (Brasil, 2009e, p. 15), fornecendo "um quadro que possibilita identificar o que vai bem e o que vai mal” (Brasil, 2009e, p. 15). Parâmetros são materializados nos indicadores (Brasil, 2006c) mensuráveis, são da ordem do concreto, da prática (Brasil, 2009e).

No âmbito da Educação Básica, o IDEB (Índice de Desenvolvimento da Educação Básica) é um exemplo de indicador que atesta a qualidade do ensino oferecido, tendo como base de cálculo tanto os dados aferidos pelo INEP por meio do SAEB, quanto os dados apurados pelo censo escolar (Brasil, 2003; 2009c). O IDEB é apresentado como termômetro da qualidade do ensino e associado às ações de medir, aferir e avaliar. Ao mesmo tempo, é um indicador capaz de comparar e classificar resultados obtidos. É medida do conhecimento e prestação social de contas.

\begin{abstract}
O Ideb [Índice de Desenvolvimento da Educação Básica] é um dos eixos do PDE [Plano de Desenvolvimento da Educação] que permite realizar uma transparente prestação de contas para a sociedade de como está a educação em nossas escolas. Assim, a avaliação passa a ser a primeira ação concreta para se aderir às metas do compromisso e receber o apoio técnico / financeiro do MEC [Ministério da Educação], para que a educação brasileira dê um salto de qualidade (Brasil, 2008a, p. 4).
\end{abstract}

A avaliação nacional é entendida como capaz de subsidiar o planejamento das políticas públicas (Brasil, 2003; 2004b; 2008a), “[...] contribuir para o desenvolvimento, em todos os níveis educativos, de uma 
cultura avaliativa que estimule a melhoria dos padrões de qualidade e equidade da educação brasileira e adequados controles sociais de seus resultados" (Brasil, 2005, p. 17) e impulsionar a reflexão “[...] sobre o progresso do País e seu desenvolvimento social e econômico” (Brasil, 2004b, p. 42).

No âmbito dessa política de avaliação da qualidade, receia-se que as escolas foquem seu trabalho apenas no que é avaliado nas provas externas, produzindo a inversão das referências para o trabalho pedagógico: abandono de suas propostas curriculares, em função do foco nos resultados e padrões estabelecidos pelos exames nacionais. "Assim, a avaliação deixa de ser parte do desenvolvimento do currículo, passando a ocupar o lugar dele no processo educacional" (Brasil, 2009c, p. 62). A avaliação deve "[...] considerar as dimensões extrínsecas ou extraescolares que permeiam tal temática” (Brasil, 2007c, p. 15), bem como não perder de vista "[...] a importância, nesse processo, das dimensões que ocorrem no âmbito intraescolar” (Brasil, 2007c, p. 20), pois “[...] a qualidade da educação não se mede somente pelos resultados obtidos pelos alunos nos testes de aprendizagem" (Brasil, 2006c, p. 20). A qualidade se viabiliza, entre outras formas, por meio do estabelecimento de parâmetros ou diretrizes curriculares (Brasil, 2010), sendo o currículo de qualidade aquele que apresenta a seleção de conhecimentos relevantes e significativos.

Julgamos que uma educação de qualidade, como a que defendemos, requer a seleção de conhecimentos relevantes, que incentivem mudanças individuais e sociais, assim como formas de organização e de distribuição dos conhecimentos escolares que possibilitem sua apreensão e sua crítica. Tais processos necessariamente implicam o diálogo com os saberes disciplinares assim como com outros saberes socialmente produzidos (Brasil, 2007a, p. 21).

Os saberes disciplinares são somados e ao mesmo tempo distinguidos dos outros saberes, os saberes que parecem ser vinculados à diversidade social, onde se parece querer restringir a possibilidade de expressão da diferença. Conflitos e contestação entre saberes não são enunciados, como se fosse possível separar os saberes, dispô-los em segmentos e apagar a contingência que os constitui.

Simultaneamente, é refutada a ideia de currículo de qualidade como aquele que prepara para os vestibulares, para a entrada na universidade e nas empresas, para aprovação em processos de seleção rígidos cujos critérios de mérito e sucesso são importantes (Brasil, 2007b). Também o currículo único é criticado, alegando ser algo idealizado para uma minoria que terá sucesso e que, por consequência, desconsidera as desigualdades de condições entre os alunos. Igualmente são realizados questionamentos de toda ordem às práticas avaliativas centradas nos resultados. Mas tais críticas parecem não desestabilizar a hegemonia em torno dos discursos que fortalecem a ideia de currículo centraliza- 
do. Parecem se ressentir da impossibilidade de agir de outra maneira e de sua condição de distanciamento da almejada transformação social, do projeto de distribuição de justiça social.

\begin{abstract}
Lamentavelmente, esses questionamentos não têm indicado alternativas para o aperfeiçoamento das avaliações nacionais. Como se sabe, as avaliações ENEM e Prova Brasil vem-se constituindo em políticas de Estado que subsidiam os sistemas na formulação de políticas públicas de equidade, bem como proporcionam elementos aos municípios e escolas para localizarem as suas fragilidades e promoverem ações, na tentativa de superá-las, por meio de metas integradas. Além disso, é proposta do CNE [Conselho Nacional de Educação] o estabelecimento de uma Base Nacional Comum que terá como um dos objetivos nortear as avaliações e a elaboração de livros didáticos e de outros documentos pedagógicos (Brasil, 2010, p. 7).
\end{abstract}

As práticas avaliativas centradas nos resultados se multiplicam em todas as esferas de ensino e não se produz um discurso que desnaturalize seus efeitos. Como foi discutido em Matheus e Lopes (2012), as ideias de eficiência e de eficácia que se buscou expulsar na construção do sentido de qualidade social retornam ao processo de significação na definição dos instrumentos e indicadores de avaliação da aprendizagem dos conteúdos que compõem o currículo nacional. As avaliações nacionais estão, da mesma forma, constituindo o discurso de que o ensino tem que ser eficaz: a eficácia do ensino será constatada nos resultados de aquisição de conteúdos e competências identificados em tais exames.

Parece-nos, de momento, importante investigar que processos discursivos levam a que esses projetos de qualidade vinculados a valores entendidos como sociais e a valores significados como de mercado, ao disputarem a representação do universal, acabem por se articular. Considerando que os textos curriculares são produzidos como tentativas de fixação discursiva da significação do currículo, o que favorece sua constituição híbrida, visando a promover a almejada educação de qualidade? O que potencializa o esvaziamento do significante qualidade nas atuais políticas de currículo?

Seria possível argumentar que houve uma apropriação indevida, que desvirtua o discurso de qualidade social da educação. Parece-nos, contudo, que seria simplificar um processo político complexo e multifacetado. É característico de um texto político ser ambíguo, por vezes incoerente e inconsistente, como decorrência das articulações necessárias a sua constituição política e, como todo texto, sofre o acréscimo e a corrosão atinentes à tradução, suplementando de forma sem fim sentidos supostos como originais.

Interessa-nos entender, do ponto de vista pedagógico, quais elementos desses discursos favorecem sua articulação no momento atual 
e quais sentidos são bloqueados por essa articulação. Optamos por lançar a discussão de que ambos os discursos anteriormente construídos de forma antagônica têm sua articulação favorecida porque mantêm em comum um imaginário educacional capaz de restringir o currículo ao ensino e à instrução, produzindo uma equivalência entre conhecimento relevante e conhecimento mensurável.

As atuais propostas curriculares não inventam novos modos de conceber o currículo. Restringem-se a uma concepção objetivista de conhecimento, tornando possível a articulação entre o discurso de distribuição desse conhecimento de forma igualitária, entendido como capaz de produzir a qualidade social da educação, e o discurso de garantia do acesso ao conhecimento, também difundido pelos discursos da qualidade que se pretende total. Há assim uma equivalência entre sentidos de conhecimento que favorece a hegemonia de uma política centralizada de currículo e de seus modos de avaliar, articulando o que, nos anos 1990, muitos de nós talvez tenhamos julgado impossível de ser articulado.

\section{Conclusões}

No caso da política de currículo analisada aqui, o significante qualidade representa tanto demandas por um currículo voltado para a distribuição igualitária do conhecimento quanto demandas por mensuração de resultados estipulados em termos do currículo aprendido. O conhecimento, para finalidades diferentes, tende a ser objetivado em ambas as cadeias de equivalência antagônicas - qualidade social e qualidade que se pretende total. No discurso de qualidade social, o conhecimento é considerado fundamental para tornar mais igualitárias as condições de ensino para o conjunto dos que têm acesso à educação e, consequentemente, para promover a justiça social. O desenvolvimento do aluno na escola é, por sua vez, vinculado ao desenvolvimento social da nação, ao mesmo tempo que assume traços da perspectiva crítica de currículo, na qual o significante conhecimento carreia os sentidos de emancipação, libertação humana e crítica social. No discurso da qualidade que se quer total, o conhecimento é importante para garantir que a educação favoreça os níveis instrucionais supostos como necessários ao desenvolvimento profissional e social, tornando equivalentes as finalidades do indivíduo, as finalidades do mercado e do país. São carreados, assim, sentidos das perspectivas instrumentais de currículo, nos quais ressoam matizes de uma ideia de eficiência social, que se pensa como garantida pelo foco no resultado da aprendizagem do alunado.

Em ambos os discursos, o conhecimento torna-se um dado externo ao sujeito (Macedo, 2012), a ser adquirido no processo de escolarização. O processo educacional assume a finalidade de instruir, distribuir conhecimentos, especialmente disciplinares, garantir o acesso ao saber legitimado, com traços objetivistas e realistas. O conhecimento é 
Sentidos de Qualidade na Política de Currículo (2003-2012)

desvinculado das dinâmicas sociais de produção cultural associadas ao currículo e fixado a posições de sujeito: os saberes historicamente construídos, os saberes disciplinares, os saberes populares (Lopes, 2012).

Essa equivalência entre sentidos de conhecimento favorece a hibridização de sentidos da qualidade social, bandeira levantada pelos movimentos sociais, com sentidos da qualidade que se quer total, vinculados à lógica do mercado e da sociedade global. Em nome de uma sociedade mais justa, é considerado possível controlar o currículo por meio da avaliação em larga escala, bem como mensurar a qualidade dos processos educacionais por indicadores precisos, difundir o conhecimento capaz de alcançar as finalidades pretendidas, as finalidades de todos. Traços das perspectivas críticas e das perspectivas instrumentais ressoam nesses textos e tornam o conhecimento uma grande moeda de troca no processo educacional.

De forma paradoxal, a demanda por justiça social marca também a tentativa de não associar essa política exclusivamente às demandas de formação para uma vida economicamente produtiva, para dada eficiência no desempenho profissional, indutor de retornos dos investimentos na educação. Múltiplos sentidos flutuam no significante justiça social - emprego, renda, sucesso, sintonia com o mundo em mudança, consciência crítica, diminuição da desigualdade econômica e social, mobilidade social, transformação social, democratização das oportunidades, inclusão, desenvolvimento econômico do país. O conhecimento escolar é a alavanca desse (novo) projeto social. A reificação do conhecimento e a redução do currículo às finalidades de ensino permanecem em um imaginário pedagógico que conecta de forma determinista educação e desenvolvimento social, tornando possível articular discursos de qualidade.

Defendemos que tal modo de interpretar o conhecimento - algo a ser distribuído, algo que se sabe o que é por uma história (crítica) ou uma ciência (disciplinar), algo objetivo a ponto de poder ser claramente medido, algo que se desvincula das possibilidades de tradução cultural no âmbito da escola e dos processos de subjetivação - vem modelando as políticas de currículo e contribuindo para hegemonizar o projeto de centralidade curricular. Os modos instituídos de interpretar tendem a bloquear outras possibilidades curriculares, outras possíveis leituras, contribuindo para que a política instituída seja concebida como inexorável, única ontologia possível, ao invés de ser compreendida como produzida por atos de poder.

Permanece ainda a questão relativa ao antagonismo que garante tal equivalência entre sentidos de conhecimento de projetos sociais tão distintos. Trabalhamos com a hipótese de que os projetos de qualidade antagônicos acabam por se articular nesse momento, porque se colocam como visando a combater os processos sociais considerados como bloqueios ao desenvolvimento do país, sendo um deles a educação sem qualidade. A educação sem qualidade é assim uma ameaça ao desen- 
volvimento do país, e o desenvolvimento a forma de garantir a competividade internacional, de enfrentar a ameaça externa ao projeto de justiça social. Desenvolvimento, justiça social e qualidade tornam-se significantes cada vez mais borrados, nos quais múltiplos sentidos deslizam e com essa imprecisão, garantem de forma conflituosa a articulação dos que se propõem a distribuir conhecimentos para todos, muitos dos quais não se encontram articulados em outros projetos sociais.

O que se encontra sedimentado, contudo, nunca o é de uma vez por todas. Por mais sólidas que sejam as estruturas com as quais interpretamos (lemos) a textualidade política, sempre é possível desconstruí-las, apresentar outras possibilidades de leitura. Sempre estaremos no paradoxo de que fazer política implica deslocar as estruturas, é um ato de romper com o que se sabe, tendo em vista, ao mesmo tempo, de que só pensamos com o que sabemos (ou julgamos saber). Construir outros imaginários pedagógicos nos parece depender de deslocamentos do que se encontra sedimentado. Este texto é uma aposta nessa possibilidade.

Recebido em 07 de julho de 2013 Aprovado em 30 de setembro de 2013

\section{Notas}

1 Foram levantados documentos produzidos ou encomendados pelo Ministério da Educação, por meio do Conselho Nacional de Educação, da Secretaria de Educação Básica e do INEP, que versam sobre Educação Básica. A organização dos textos e a busca de significantes foram realizadas por meio do programa Wordsmith Tools, sem que a lógica de análise tenha se pautado por esse programa.

2 Congresso organizado pela Confederação Nacional de Trabalhadores em Educação (CNTE): <http://www.cnte.org.br>.

3 Ver, por exemplo, Moreira (1995; 1996; 1997), Silva; Gentili (1996; 1997).

4 Não estamos com isso afirmando que se trata de uma identidade entre os dois governos, há diferenças em muitas áreas, inclusive na área econômica. Sublinhamos aqui a continuidade acentuada no que concerne às políticas de currículo, na direção apontada anteriormente por Lopes (2004).

5 Ver reportagem publicada no Jornal O Globo, no Rio de Janeiro, Brasil, em 23 de maio de 2012, em: <http://oglobo.globo.com/educacao/projeto-do-mec-quer-unificar-curriculo-das-escolas-no-pais-3549446> (acesso em 23 de maio de 2012).

6 Para conhecer exemplos de críticas realizadas nos anos 1990 a esse discurso, sugerimos Silva; Gentili $(1996,1997)$.

7 O movimento Todos pela educação, criado em 2006, no Brasil, se apresenta como "[...] um movimento financiado exclusivamente pela iniciativa privada, que congrega sociedade civil organizada, educadores e gestores públicos que tem como objetivo contribuir para que o Brasil garanta a todas as crianças e jovens o direito à Educação Básica de qualidade” (<http://www.todospelaedu-

Educação \& Realidade, Porto Alegre, v. 39, n. 2, p. 337-357, abr./jun. 2014 
cacao.org.br>, acesso em 10 de maio de 2012). São instituições e empresas que financiam este movimento: Banco Santander, DPaschoal, Instituto Unibanco, Fundação Itaú Social, Gerdau, Instituto Camargo Correa, Fundação Bradesco, Suzano Papel e Celulose, Itaú BBA e Faber Castell. Constam ainda várias empresas e instituições como parceiros e apoiadores. Para maiores detalhes, ver: <http://www.todospelaeducacao.org.br/institucional/quem-esta-conosco/>.

8 Com base em exames aplicados aos estudantes da Educação Básica, são verificados e quantificados os níveis de aprendizagem desses mesmos alunos. A pontuação 6,0 é estabelecida como meta mínima em uma escala de 0-10.

\section{Referências}

BALL, Stephen. Education Reform: a critical and post-structural approach. Buckingham: Open University Press, 1994.

BRASIL. Ministério da Educação. Qualidade da Educação: uma nova leitura do desempenho dos estudantes da $8^{a}$ série do ensino fundamental. Brasília: MEC/Inep, 2003. Disponível em: <http://www.publicacoes.inep.gov.br/ arquivos/\%7BC00EFE24-1160-4D1A-8695-48061763945C\%7D_qualidade_educa.pdf>. Acesso em: 05 jan. 2012.

BRASIL. Ministério da Educação. O Desafio de uma Educação de Qualidade para Todos: educação no Brasil - 1990-2000. Brasília: MEC/Inep, 2004a. Disponível em: <http://www.educamococa.com.br/concursos/CONCURSO\%20 DIRETOR\%202010/O\%20desafio\%20de\%20uma\%20educa\%E7\%E3o\%20de\%20 qualidade\%20para\%20todos.pdf>. Acesso em: 17 jan. 2012.

BRASIL. Ministério da Educação. Qualidade da Educação: uma nova leitura do desempenho dos estudantes da $3^{\mathrm{a}}$ série do ensino médio. Brasília: MEC/Inep, 2004b. Disponível em: <http://www.publicacoes.inep.gov.br/ arquivos/\%7B88683CA6-09B4-4BC2-AE54-E1E5A775D1C8\%7D_qualidade_ educacao_319.pdf>. Acesso em: 27 dez. 2011.

BRASIL. Ministério da Educação. Gabinete do Ministro. Portaria No 931, de 21 de março de 2005. Sistema de Avaliação da Educação Básica - SAEB. Brasília: DOU, 2005.

BRASIL. Ministério da Educação. Orientações Curriculares para o Ensino Médio: linguagens, códigos e suas tecnologias. Brasília: MEC/SEB, 2006a. Disponível em: <http://portal.mec.gov.br/seb/arquivos/pdf/book_volume_01_internet.pdf>. Acesso em: 17 jan. 2012.

BRASIL. Ministério da Educação. Política Nacional de Educação Infantil: pelo direito das crianças de 0 a 6 anos à educação. Brasília: MEC/SEB, 2006b. Disponível em: <http://www.oei.es/quipu/brasil/pol_educ_infantil.pdf>. Acesso em: 17 jan. 2012.

BRASIL. Ministério da Educação. Parâmetros Nacionais de Qualidade para a Educação Infantil. Brasília: v.1, MEC/SEB, 2006c. Disponível em: <http://portal.mec.gov.br/seb/arquivos/pdf/Educinf/eduinfparqualvoll.pdf $>$. Acesso em: 23 de jan. 2012.

BRASIL. Ministério da Educação. Indagações sobre Currículo: currículo, conhecimento e cultura. Brasília: MEC/SEB, 2007a. Disponível em: <http://portal. mec.gov.br/seb/arquivos/pdf/Ensfund/indag3.pdf $\geq$. Acesso em: $20 \mathrm{dez} .2011$.

BRASIL. Ministério da Educação. Indagações sobre Currículo: educandos e educadores: seus direitos e o currículo. Brasília: MEC/SEB, 2007b. Disponível 
em: <http://portal.mec.gov.br/seb/arquivos/pdf/Ensfund/indag2.pdf>. Acesso em: 20 dez. 2011.

BRASIL. Ministério da Educação. A Qualidade da Educação: conceitos e definições. Brasília: v. 24, n. 22, MEC/Inep, 2007c. Disponível em: <http:// www.publicacoes.inep.gov.br/arquivos/\%7BF84EADE4-B76E-49DB-8B35D196B9568685\%7D_DISCUSS\%C3\%83O\%20N\%C2\%BA\%2024.pdf>. Acesso em: 05 jan. 2012.

BRASIL. Ministério da Educação. Plano de Desenvolvimento da Educação: SAEB 2009. Brasília: MEC/SEB/Inep, 2008a. Disponível em: <http://www.anj. org.br/jornaleeducacao/biblioteca/publicacoes/Saeb_Matriz_2009.pdf>. Acesso em: 10 jan. 2012.

BRASIL. Ministério da Educação. Provinha Brasil reflexões sobre a prática 1-2008. Brasília: MEC/SEB/Inep, 2008b. Disponível em: <http://ebookbrowse. com/reflexoes-sobre-a-pratica-1-2008-pdf-d254488621>. Acesso em: $15 \mathrm{dez}$. 2011

BRASIL. Ministério da Educação. Relatório Pedagógico ENEM 2006. Brasília: MEC/ Inep, 2008c. Disponível em: <http://ebookbrowse.com/relatorio-pedagogico-enem-2006-pdf-d199881674>. Acesso em: 08 dez. 2011.

BRASIL. Ministério da Educação. Subsídios para Diretrizes Curriculares Nacionais Específicas para a Educação Infantil. Brasília: MEC/SEB, 2009a. Disponível em: <http://portal.mec.gov.br/index.php?option=com_content\&view=art icle\&id=13867\&Itemid=936>. Acesso em: 26 nov. 2011.

BRASIL. Ministério da Educação. Subsídios para Diretrizes Curriculares Nacionais Específicas para o Ensino Fundamental. Brasília: MEC/SEB, 2009b.

BRASIL. Ministério da Educação. Subsídios para Diretrizes Curriculares Nacionais Específicas da Educação Básica. Brasília: MEC/SEB, 2009c. Disponível em: <http://portal.mec.gov.br/dmdocuments/subsidios_dcn.pdf >. Acesso em: 17 dez. 2011.

BRASIL. Ministério da Educação. Portaria CNE/CP no 10 de 6 de agosto de 2009. Indicações para Subsidiar a Construção do Plano Nacional de Educação 20112020. Brasília: 2009d. Disponível em: <http://portal.mec.gov.br/dmdocuments/ pne_200809.pdf>. Acesso em: 23 nov. 2011.

BRASIL. Ministério da Educação. Indicadores da Qualidade na Educação Infantil. Brasília: MEC/SEB, 2009e. Disponível em: <http://portal.mec.gov.br/ dmdocuments/indic_qualit_educ_infantil.pdf $>$. Acesso em: 15 jan. 2012.

BRASIL. Ministério da Educação. Parecer CNE/CEB No: 7/2010. Assunto: Diretrizes Curriculares Nacionais Gerais para a Educação Básica. Brasília: aprovado em 07/04/2010. Disponível em: <http://www.nepiec.com.br/lesgislacao/ pceb007_10.pdf >. Acesso em: 17 dez. 2011.

BRASIL. Ministério da Educação. Parecer CNE/CEB No: 05/2011. Assunto: Diretrizes Curriculares Nacionais para o Ensino Médio. Brasília: aprovado em 04/05/2011. Disponível em: <http://portal.mec.gov.br/index. php?option=com_content\&view=article\&id=12992:diretrizes-para-a-educacao-basica\&catid=323:orgaos-vinculados > . Acesso em: 03 fev. 2012.

BOWMAN, Paul. Post-Marxism Versus Cultural Studies - theory, politics and intervention. Edinburgh, Edinburgh University, 2007.

CONED. Plano Nacional de Educação: Proposta da Sociedade Brasileira. Belo Horizonte, II CONED, 1997. Disponível em: <http://www.adusp.org.br/files/ PNE/pnebra.pdf>. Acesso em: 15 maio 2013. 
LACLAU, Ernesto. La Razón Populista. Buenos Aires: Fondo de Cultura Económica, 2005.

LACLAU, Ernesto. Emancipação e Diferença. Rio de Janeiro, Editora da UERJ, coordenação e revisão técnica de Alice Casimiro Lopes e Elizabeth Macedo, 2011.

LOPES, Alice Casimiro. Políticas Curriculares: continuidade ou mudança de rumos? Revista Brasileira de Educação, São Paulo, v. 1, n. 26, p. 109-118, 2004.

LOPES, Alice Casimiro. Cultura e Diferença nas Políticas de Currículo: a discussão sobre hegemonia. In: PERES, Eliane; TRAVERSINI, Clarice; EGGERT, Edla; BONIN, Iara (Org.). Trajetórias e Processos de Ensinar e Aprender: sujeitos, currículo e cultura. Porto Alegre: EdiPUC-RS, 2008. P. 59-78.

LOPES, Alice Casimiro. Currículo, Política, Cultura. In: SANTOS, Lucíola; DALBEN, Angela; DINIZ, Julio; LEAL, Leiva (Org.). Convergências e Tensões no Campo da Formação e do Trabalho Docente. Belo Horizonte: Autêntica, 2010. P. 23-37.

LOPES, Alice Casimiro. A Qualidade da Escola Pública: uma questão de currículo? In: VIANA, F.; OLIVEIRA, Marcus Aurelio; FONSECA, Nelma; LIMA, Rita Cristina (Org.). A Qualidade da Escola Pública no Brasil. Belo Horizonte: Mazza Editora, 2012. P. 9-25.

MACEDO, Elizabeth. Currículo e Conhecimento: aproximações entre educação e ensino. Cadernos de Pesquisa (Fundação Carlos Chagas. Impresso), v. 42, p. 716-737, 2012

MARCHART, Oliver. Post-foundational Political Thought: political difference in Nancy, Lefort, Badiou and Laclau. Edinburgh: Edinburgh University Press, 2007.

MATHEUS, Danielle; LOPES, Alice. Currículo e o Discurso da Qualidade Social na Educação. In: FERRAÇO, Carlos; CARVALHO, Janete (Org.). Currículos, Pesquisas, Conhecimentos e Produção de Subjetividades. Petrópolis/ Vitória: Editora, DPAllii/NUPEC/UFES, 2012. P. 163-182.

MOREIRA, Antonio Flavio Barbosa. Neoliberalismo, Currículo Nacional e Avaliação. In: SILVA, Luiz Heron da; AZEVEDO, José Clóvis de (Org.). Reestruturação Curricular. Petrópolis: Vozes, 1995. P. 94-107.

MOREIRA, Antonio Flavio Barbosa. Os Parâmetros Curriculares Nacionais em Questão. Educação \& Realidade, Porto Alegre, v. 21, n. 1, p. 9-22, jan./jun. 1996.

MOREIRA, Antonio Flavio Barbosa. A Psicologia... e o Resto: o currículo segundo César Coll. Cadernos de Pesquisa, São Paulo, n. 100, p. 93-107, mar. 1997.

PARTIDO DOS TRABALHADORES. Programa de Governo 2002. São Paulo: 2002. Disponível em: <wwwl.uol.com.br/fernandorodrigues/arquivos/.../plano2002-lula.doc >. Acesso em: 15 jan. 2013.

PARTIDO DOS TRABALHADORES. Lula Presidente: programa de governo 2007/2010. São Paulo: 2007. Disponível em: <http://bvsms.saude.gov.br/bvs/publicacoes/plano_governo.pdf>. Acesso em: 15 jan. 2013.

PARTIDO DOS TRABALHADORES. Os Treze Compromissos Programáticos de Dilma Roussef para Debate na Sociedade Brasileira. São Paulo: 2010. Disponível em: <http://deputados.democratas.org.br/pdf/Compromissos_Programaticos_Dilma_13\%20Pontos_.pdf>. Acesso em: 15 jan. 2013.

PARTIDO DOS TRABALHADORES. Uma Escola do Tamanho do Brasil (proposta da Campanha Presidencial). 2002. Disponível em: <http://www.fpabramo. org.br/uploads/umaescoladotamanhodobrasil.pdf>. Acesso em: 24 mar. 2013.

356 Educação \& Realidade, Porto Alegre, v. 39, n. 2, p. 337-357, abr./jun. 2014 Disponível em: <http://www.ufrgs.br/edu_realidade> 
SILVA, Tomaz Tadeu da; GENTILI, Pablo (Org.). Neoliberalismo, Qualidade Total e Educação. Petrópolis: Vozes, 1996. P. 9-30.

SILVA, Tomaz Tadeu da; GENTILI, Pablo (Org.). Escola S. A.: quem ganha e quem perde no mercado educacional do neoliberalismo. Brasília: CNTE, 1997.

WOLFREYS, Julian. Compreender Derrida. Petrópolis, Rio de Janeiro: Vozes, 2009.

Danielle dos Santos Matheus é doutora em Educação pelo Programa de Pós-graduação em Educação <www.proped.pro.br> da Universidade do Estado do Rio de Janeiro (UERJ), professora do Colégio Pedro II.

E-mail: danismatheus@yahoo.com.br

Alice Casimiro Lopes é professora do Programa de Pós-graduação em Educação <www.proped.pro.br> da Universidade do Estado do Rio de Janeiro (UERJ), pesquisadora nível 1C do CNPq, Cientista do Nosso Estado Faperj, Procientista UERJ, coordenadora do grupo de pesquisa Políticas de Currículo e Cultura <www.curriculo-uerj.pro.br $>$, membro titular do CA-Ed do CNPq.

E-mail: alicecasimirolopes@gmail.com 